\title{
Comparative observation of two types of limb salvage surgery on limb function and quality of life in patients with knee joint osteosarcoma
}

\section{Zi-Wei Hou}

Shandong University of Traditional Chinese Medicine

\section{Wen-Zhe Bai}

Shandong University of Traditional Chinese Medicine Affiliated Hospital

\section{Ming Xu}

960th Hospital of PLA

\section{Kai Zheng}

960th Hospital of PLA

XiuChun Yu ( $\nabla$ yxch48@vip.sina.com )

960th Hospital of PLA

\section{Research Article}

Keywords: Osteosarcoma, Joint preservation limb salvage, Knee function, Quality of life

Posted Date: September 21st, 2021

DOl: https://doi.org/10.21203/rs.3.rs-99975/v2

License: (9) This work is licensed under a Creative Commons Attribution 4.0 International License. Read Full License 


\section{Abstract \\ Background}

We compared the differences of Joint-preservation Limb Salvage (JPLS) and Joint-prosthesis Replacement Surgery (JPRS) on limb function and quality of life in patients with osteosarcoma in the knee.

\section{Methods}

This retrospective study evaluated the postoperative outcomes of patients treated with JPLS and JPRS for osteosarcoma around the knee between November 2000 and January 2019. All patients were followed up at 1 year postoperatively. Patients' lower extremity function, knee function, and quality of life were evaluated during follow-up using the MSTS score, IKDC score, and SF-36 score.

\section{Results}

The patients were divided into two groups: the joint-preservation group (16) and the prostheticreplacement group (19). All 35 patients received a successful operation, and all incisions healed in one stage after surgery. At 12 months after the operation, the median MTST score in the joint-preservation group was 27(range 24 to30), higher than 24(range 13 to 30 ) in the prosthetic-replacement group ( $\mathrm{P}<$ 0.05 , Table 2). The median IKDC score in the joint-preservation group was 82.5 (range 53 to 95), higher than the 60 (range 41 to 80 ) in the prosthetic- replacement group $(P<0.05$, Table 2). The SF-36 scores of physiological and social functions were higher in the joint-preserving group than those in the prostheticreplacement group $(P<0.05)$, and there were no significant differences between the groups in the other indexes $(P>0.05)$. Comparing the distribution of each item in the MSTS and IKDC scoring criteria between the joint-preservation and the prosthetic-replacement group revealed that the limb function, pain, satisfaction, support assistance, and the walking and gait of the joint-preservation group were superior to those of the prosthetic-replacement group $(P<0.05)$. There was no significant difference in knee flexion between the two groups $(P>0.05)$. However, the joint-preservation group performed superior to the prosthesis-replacement group in terms of pain, swelling, twisting, softening of the leg, movement downstairs, sitting up from a chair, kneeling, squatting, running straight, jumping up with the injured leg and landing, and quickly stopping or starting $(P<0.05)$.

\section{Conclusion}

Compared with joint-prosthesis replacement surgery, joint-preservation limb salvage performed better joint function and quality of life. The findings provide a signal of superiority for JPLS to JPRS but further investigation is warranted in multicentre trials. 


\section{Background}

Osteosarcoma (OS) is a most common primary malignant bone tumor, and $80 \%-90 \%$ of these occur in the metaphysis of the long bones of the extremities, in particular around the knee joint (distal femur and proximal tibia)[1]. Approximately $70 \%$ of osteosarcoma occurs around the knee[2]. With the wide application of neoadjuvant chemotherapy and the rapid development of bone tumor surgery, limb salvage surgery has become the primary surgical treatment of OS[3]. Pathological changes in some osteosarcoma patients are mainly localized above the diaphysis or metaphysis, and these tumors do not break through the epiphyseal plate to invade the epiphysis at diagnosis[24]. Therefore, the jointpreservation limb salvage (JPLS) treatment should be applied in clinical practice[4].

Compared with joint-prosthesis replacement surgery (JPRS), JPLS can better preserve the ligaments and joint capsule of the patient, which is beneficial to the recovery of the joint function[16, 24].

Simultaneously, long-term complications, such as limb shortening, prosthesis loosening, and infection can be overcome, realizing the aim of biological reconstruction[5]. At present, with the improvement of survival and limb salvage rates of OS, both the recovery of limb function and the pursuit of high quality of life (Qol) are of importance. The modern medical model of society-psychology-biology-medicine has made Qol an important index of Clinical Curative Effect Evaluation. Therefore, it is necessary to explore the Qol of patients.

To compare the clinical outcomes of JPLS and JPRS, we retrospectively analyzed the lower extremity function, knee joint function, and Qol of 35 patients with osteosarcoma around the knee joint treated in our hospital between November 2000 and January 2019.

\section{Methods}

\section{Patients}

All case data were obtained from 35 patients with osteosarcoma around the knee admitted to our hospital between November 2000 and January 2019. The patients were divided into two groups in February 2019: the joint-preservation group (16 cases) and the prosthetic-replacement group (19 cases), all patients were followed-up for at least two years. We retrospectively analyzed the case data and included 19 males and 16 females, aged 16 to 49 (average 28.46) years.

\section{Inclusion and exclusion criteria}

The inclusion criteria for this study were (1) patients who were pathologically confirmed to have primary osteosarcoma; (2) patients who completed neoadjuvant chemotherapy; (3) the distal femur and proximal tibia is the primary site of OS; (4) patients who received surgical treatment, including limb salvage and total knee arthroplasty; (5) the follow-up period was at least 12 months; (6) patients were without mental illness and able to understand and complete the questionnaires independently or under the guidance of the doctor; (7) patients who provided informed consent. The exclusion criteria were (1) involvement of 
heart, brain, kidney, and blood and other serious diseases; (2) incomplete case data; (3) patients diagnosed with metastasis; (4) patients who existed pathological fracture before surgery.

\section{Evaluation Of Tumor Location}

The tumor boundary was identified by magnetic resonance imaging (MRI) before and after chemotherapy. To determine the appropriate surgical management, tumors were divided into 3 types according to the correlation between the osteosarcoma and epiphysis, and the distance between the tumor and the line connecting the height points of the femoral condyles (Insall line) (Fig. 1).

Type I: The tumor is located at least $1 \mathrm{~cm}$ above the lower boundary of the Insall line. Reconstruction in 13 patients was performed using inactivated autograft replantation with joint preservation.

Type II: The tumor is located near the Insall line. 3 patients conformed to this type and were treated by JPLS.

Type III: The tumor crosses the Insall line and has invaded the femoral condyles. Reconstruction was performed in all patients using custom-made rotating hinge knee prostheses.

\section{Preoperative treatment}

All 35 patients received a chemotherapy regimen consisting of cisplatin-ifosfamide-adriamycin(we called DIA[6]) for preoperative chemotherapy. We administered a course of ifosfamide and adriamycin in the first week and ifosfamide and adriamycin in the second week; 2 weeks apart, we administered a second course of chemotherapy in the fifth week. The drug doses were as follows: $120 \mathrm{mg} / \mathrm{m}^{2}$ intravenous drip once; ifosfamide $2.0 \mathrm{~g} / \mathrm{m}^{2}$ daily intravenous drip, immediately, 6 hours, and 8 hours after treatment with mesna $1200 \mathrm{mg} / \mathrm{m}^{2}$ intravenous drip for 5 days; adriamycin $30 \mathrm{mg} / \mathrm{m}^{2}$ intravenous drip for 3 days.

\section{Surgical Technique}

\section{Joint-preservation Limb Salvage}

The procedure was performed under epidural or general anesthesia. The patient was placed in a supine position with a pneumatic tourniquet applied at the base of the thigh. An incision of $30 \mathrm{~cm}$ in length was made in the medial parapatellar region before the knee. The skin, subcutaneous tissue, and fascial layer were incised layer by layer from the space between the right rectus femoris to the vastus medialis. The distal and middle femurs were exposed using the medial patellar approach. The femoral shaft was transected about $11 \mathrm{~cm}$ from the articular surface of the femoral condyle.Then the distal end was lifted and the femoral vessels were sharply separated at the edge of the joint capsule. The tumor nutrient vessels were cut and ligated. The medial and lateral head of the gastrocnemius muscle, the medial and lateral collateral ligaments, the joint capsule, and the anterior and posterior cruciate ligaments were cut, and the distal femoral tumor segment was removed entirely. The tourniquet was loosened, the bleeding 
was stopped, and the tumor bed was soaked with saline at $42^{\circ} \mathrm{C}$. The removed tumor segment was fenestrated behind the intercondylar notch, the tumor tissue in the periosteum, medullary cavity and soft tissue were thoroughly scraped, the medial plate or lateral plate of the distal femur with appropriate length were selected and placed inside or outside the tumor segment, and the screw holes were predrilled for future use. The tumor segment and steel plate were immersed entirely in absolute ethanol for inactivation for $30 \mathrm{~min}$. The bone cement was reconciled and placed into the tumor segment. The plate was placed in the appropriate position and screwed into screw fixation. The inactivated tumor segment was replanted, holes were drilled in the plate, and several screws were used for fixation(Fig. 2). The knee joint was reduced, thoroughly irrigated with $3 \%$ hydrogen peroxide solution and saline, and the surgical incision was closed layer by layer by suture. A negative pressure drainage tube was indwelled, the wound was dressed sterile, and a plaster brace was fixed externally.

All the 16 patients underwent tumor segmentectomy and replantation, 9 patients had intramedullary nail fixation, 5 patients had a plate fixation, and 2 patients had external fixator fixation.

We believe that the indications of JPLS are as follows: (1) The tumor must be located in the diaphysis or

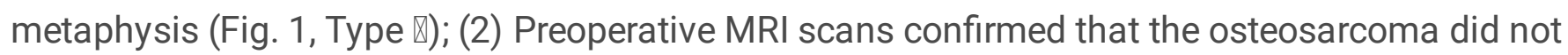
penetrate the epiphyseal plate to invade the epiphysis, which was further confirmed by histopathology tests post-surgery. (3) The therapeutic principles of neoadjuvant chemotherapy must be strictly followed, and surgery must be done under the protection of effective preoperative chemotherapy. We also recommend that surgery be performed by a bone oncologist who specialises in osteosarcoma surgery and bone defect repair techniques.

\section{Joint-prosthesis Replacement Surgery}

The procedure was performed under epidural or general anesthesia. The patient was placed in a supine position with a pneumatic tourniquet applied at the base of the thigh. A longitudinal incision was made of $10 \mathrm{~cm}$ centered on the fibular head. The skin, subcutaneous tissue, and fascial layer were incised layer by layer to expose the fibular head while protecting the common gastrocnemius nerve. Three $\mathrm{cm}$ below the lower fibular head, the fibula was amputated. An anteromedial "S" -shaped incision was made in the knee, and the skin, subcutaneous tissue, and fascial layer were incised layer by layer. Then the calf patellar flap was freed to both sides to expose the tibia, and the joint capsule was incised; the tendon insertion point was cut outside the periosteum at the tibial insertion point and everted. The medial and lateral tibial tumors were freed, the popliteal vessels were exposed and protected on the deep surface of the medial gastrocnemius muscle in the popliteal fossa. The medial joint capsule and the medial goose foot tendon insertion point were incised. The anterior spreading muscle was incised laterally and acutely freed outside the tibial periosteum. Then,the length of the osteotomy of the proximal tibial tumor segment was measured, the periosteum was dissected at the osteotomy, and the tibial tumor segment was lifted retrogradely using a wire saw. The nerves and peroneal vessels of the anterior spreading and posterior tibial vessels were separated and protected on the deep surface of the soleus muscle. The tumor segment was removed entirely along with the fibula. The tibial medullary cavity was reamed, the cruciate ligament 
of the intercondylar notch was removed, and the femoral medullary canal was located. The distal bone resection was $9 \mathrm{~mm}$, the bone resection module was selected, the anterior and posterior condylar bone resection was performed in turn, and the prosthesis trial was tried and placed. Then we placed the medullary plug in the femoral medullary cavity, reconciled the bone cement, injected the bone cement into the cavity, installed the prosthesis of the corresponding model, placed the medullary needle in the tibia, and installed the connecting device. We then took a patch of the appropriate size to cover and fix on the tibial prosthesis's surface, excised the distal end of the medial gastrocnemius muscle, pulled it to the front, and covered the surface of the prosthesis. Finally, the tendon was sutured to the gastrocnemius muscle bundle; we sutured the joint capsule, sutured and closed the surgical incision layer by layer, indwelled the negative pressure drainage tube, and fixed it with a sterile dressing.

We performed 19 cases of tumor segmentectomy and artificial knee arthroplasty, including 17 cases of primary prosthetic joint replacement and two cases of secondary revision joint replacement.

\section{Postoperative Treatment}

Antibiotics were routinely applied for 48 hours postoperatively to prevent infection. The time of drainage tube removal was determined by drainage volume $<50 \mathrm{ml} / 24 \mathrm{~h}$. Patients in the JPRS group were bedridden for one week without using an external brace, and those in the JPLS group were bedridden for six weeks with the use of an external brace. In both groups, the stitches were removed 12-14 days after surgery, and postoperative chemotherapy was started. The dose and type of drugs were determined based on the postoperative tumor cell necrosis rate. In the JPRS group, full weight-bearing was possible after three months of postoperative crutches use. In the JPLS group, external fixation was removed eight weeks after surgery, functional knee exercising was started, and double crutches were used to get to the ground. Full weight-bearing in this group was possible after four months of crutches use.

Plain anteroposterior and lateral radiographic examinations were performed every three months for two years, then bi-annually for a further three years, and annually after that. All included patients who completed at least six postoperative DIA[5] chemotherapy courses.

\section{Observation Indicators}

At 12 months after surgery, the lower extremity function was assessed using the Musculoskeletal Tumor Society (MSTS) [7], knee function was evaluated using the International Knee Documentation Committee (IKDC) Subjective Knee Score[8], and physical function, role physical, bodily pain, general health, energy, social function, role-emotional, mental health, and health changes were evaluated using the Medical Study 36-item short-form health outcomes survey (SF-36) questionnaire[9].

\section{Statistical Analysis}

Based on the small sample size, data are presented as median and range and were analyzed using SPSS 22.0 software (IBM, Armonk, NY, USA). The postoperative MSTS score, IKDC score, SF-36 item scores, and each item of the MSTS and IKDC scores were compared between the two groups using the Mann-Whitney $U$ test. $\mathrm{P}<0.05$ was considered statistically significant. 


\section{Results}

\section{General Data}

All patients received a successful operation, and no intraoperative abnormalities or serious complications occurred. The postoperative incisions healed on the first intention. The joint-preservation group was followed up for 63 (12-128) months, of which four cases underwent open reduction, ligation, and internal fixation due to inactivated bone fracture 2-9 months after the operation. One case underwent extended resection of the tumor twice due to soft tissue recurrence within 11 months after surgery. The above five cases were followed up for 12 months after the operation. The prosthesis-replacement group was followed up for 53 (12-121) months. Two cases underwent knee prosthesis revision surgery due to prosthesis dislocation and loosening six and eight years after the operation. At 12 months after surgery, we did not find any abnormalities.

Table 1

General Data of 35 patients

\begin{tabular}{|c|c|c|}
\hline General Date & Joint Preservation & Prosthetic replacement \\
\hline \multicolumn{3}{|l|}{ age } \\
\hline$₫ 30$ year old & 7 & 13 \\
\hline$\geq 30$ year old & 9 & 6 \\
\hline \multicolumn{3}{|l|}{ sex } \\
\hline male & 10 & 9 \\
\hline female & 6 & 10 \\
\hline \multicolumn{3}{|l|}{ tumor location } \\
\hline femur & 12 & 13 \\
\hline tibia & 4 & 6 \\
\hline \multicolumn{3}{|c|}{ duration of disease } \\
\hline$\leq 14$ months & 6 & 9 \\
\hline$\geq 14$ months & 10 & 10 \\
\hline \multicolumn{3}{|c|}{ Enneking stage } \\
\hline \a & 13 & 16 \\
\hline$\nabla b$ & 3 & 3 \\
\hline
\end{tabular}


The median MTST score in the joint-preservation group was 27(range 24 to30), higher than 24(range 13 to 30$)$ in the prosthetic-replacement group $(P<0.05$, Table 2$)$. The median IKDC score in the jointpreservation group was 82.5(range 53 to 95), higher than the 60(range 41 to 80 ) in the prostheticreplacement group $(P<0.05$, Table 2$)$.

\section{Quality of Life (QOL)}

At 12 months after surgery, the median physical functioning score in the joint-preservation group was 75(range 50 to 80), higher than 50(range 15 to 80) in the prosthesis-replacement group $(P<0.05$, Table 2).The median social functioning score in the joint-preservation was 93.75 (range 62.5 to 112.5), higher than 75(range 25 to 112.5) in the prosthesis-replacement group $(P<0.05$, Table 2). There were no significant differences in other indicators between the groups $(P>0.05$, Table 2$)$.

Table 2

Comparative features between two groups

\begin{tabular}{|llll|}
\hline Comparative Features & Joint Preservation & Prosthetic replacement & $P$ Value \\
\hline Postoperative MSTS score & Median(Min-Max) & Median(Min-Max) & \\
\hline Postoperative IKDC score & $82.5(53-95)$ & $60(41-80)$ & 0.001 \\
\hline Postoperative SF-36 Score & & & 0.001 \\
\hline Physical Functioning & $75(50-80)$ & $50(15-80)$ & \\
\hline Role-Physical & $50(25-100)$ & $50(0-100)$ & 0.001 \\
\hline Bodily Pain & $84(31-100)$ & $62(21-100)$ & 0.128 \\
\hline General Health & $77.5(35-100)$ & $70(40-100)$ & 0.084 \\
\hline Vitality & $75(50-120)$ & $70(15-100)$ & 0.209 \\
\hline Social Functioning & $93.75(62.5-112.5)$ & $75(25-112.5)$ & 0.153 \\
\hline Role-Emotional & $100(33.3-100)$ & $100(0-100)$ & 0.001 \\
\hline Mental Health & $76(44-100)$ & $72(20-100)$ & 0.432 \\
\hline Reported Health Transition & $75(50-100)$ & $75(0-100)$ & 0.609 \\
\hline
\end{tabular}

\section{Comparison of MSTS and IKDC Score Items}

In the comparison of MSTS items,the function, pain, satisfaction, support assistance, walking, and gait in the joint-preservation group were superior to those in the prosthesis-replacement group $(P<0.05$, Table 3$)$. 
In the comparison of IKDC items, except for the sitting with a bent knee, the joint-preservation group was superior to the prosthesis-replacement group $(P<0.05$, Table 4$)$. 
Table 3

Comparison of MSTS Score Item Distribution

\begin{tabular}{|c|c|c|c|c|}
\hline Observaton items & Items & $\begin{array}{l}\text { Joint } \\
\text { Preservation,N(\%) }\end{array}$ & $\begin{array}{l}\text { Prosthetic } \\
\text { replacementN(\%) }\end{array}$ & $\stackrel{P}{\text { Value }}$ \\
\hline \multirow[t]{5}{*}{ Function } & Partial disability & $0(0)$ & $3(15.79 \%)$ & \multirow[t]{5}{*}{0.017} \\
\hline & Intermediate & $1(6.25 \%)$ & $2(10.53 \%)$ & \\
\hline & $\begin{array}{l}\text { Recreational } \\
\text { restriction }\end{array}$ & $1(6.25 \%)$ & $6(31.57 \%)$ & \\
\hline & Intermediate & $10(62.5 \%)$ & $8(42.11 \%)$ & \\
\hline & No restriction & $4(25 \%)$ & $0(0)$ & \\
\hline \multirow[t]{4}{*}{ Pain } & Intermediate & $0(0)$ & $1(5.26 \%)$ & \multirow[t]{4}{*}{0.000} \\
\hline & Modest & $0(0)$ & $5(26.32 \%)$ & \\
\hline & Intermediate & $2(12.5 \%)$ & $10(52.63 \%)$ & \\
\hline & None & $14(87.5 \%)$ & $3(15.79 \%)$ & \\
\hline \multirow{5}{*}{$\begin{array}{l}\text { Emotional } \\
\text { acceptance }\end{array}$} & Accepts & $0(0)$ & $1(5.26 \%)$ & \multirow[t]{5}{*}{0.010} \\
\hline & Intermediate & $0(0)$ & $2(10.53 \%)$ & \\
\hline & Satisfied & $0(0)$ & $5(26.32 \%)$ & \\
\hline & Intermediate & $10(62.5 \%)$ & $10(52.63 \%)$ & \\
\hline & Enthused & $6(37.5 \%)$ & $1(5.26 \%)$ & \\
\hline \multirow[t]{5}{*}{ Supports } & 2 cane crutches & $0(0)$ & $1(5.26 \%)$ & \multirow[t]{5}{*}{0.004} \\
\hline & 1 cane crutch & $0(0)$ & $1(5.26 \%)$ & \\
\hline & Brace & $0(0)$ & $3(15.79 \%)$ & \\
\hline & Intermediate & $1(6.25 \%)$ & $2(10.53 \%)$ & \\
\hline & None & 15(93.75\%) & $12(63.16 \%)$ & \\
\hline \multirow[t]{5}{*}{ Walking } & Inside Only & $0(0)$ & $1(5.26 \%)$ & \multirow[t]{5}{*}{0.000} \\
\hline & Intermediate & $0(0)$ & $2(10.53 \%)$ & \\
\hline & Limited & $0(0)$ & $4(21.05 \%)$ & \\
\hline & Intermediate & $1(6.25 \%)$ & $8(42.11 \%)$ & \\
\hline & Unlimited & 15(93.75\%) & $4(21.05 \%)$ & \\
\hline \multirow[t]{2}{*}{ Gait } & Minor HACP & $0(0)$ & $1(5.26 \%)$ & \multirow[t]{2}{*}{0.016} \\
\hline & Intermediate & $0(0)$ & $4(21.05 \%)$ & \\
\hline
\end{tabular}




\begin{tabular}{|lllll|}
\hline Observaton items & Items & $\begin{array}{l}\text { Joint } \\
\text { Preservation,N(\%) }\end{array}$ & $\begin{array}{l}\text { Prosthetic } \\
\text { replacementN(\%) }\end{array}$ & Value \\
\hline & Minor cosmetic & $0(0)$ & $3(15.79 \%)$ \\
\hline Intermediate & $9(56.25 \%)$ & $9(47.37 \%)$ \\
\hline Normal & $7(43.75 \%)$ & $2(10.53 \%)$ \\
\hline
\end{tabular}


Table 4

Comparison of IKDC Score Item Distribution

\begin{tabular}{|c|c|c|c|c|}
\hline Observation items & Items & $\begin{array}{l}\text { Joint } \\
\text { Preservation }\end{array}$ & $\begin{array}{l}\text { Prosthetic } \\
\text { replacement }\end{array}$ & $P$ \\
\hline \multirow{5}{*}{$\begin{array}{l}\text { Highest activity } \\
\text { without pain }\end{array}$} & Very strenuous activities & $4(25 \%)$ & $0(0)$ & \multirow[t]{5}{*}{0.000} \\
\hline & Strenuous activities & $5(31.25 \%)$ & $0(0)$ & \\
\hline & Moderate activities & $7(43.75 \%)$ & $8(42.10 \%)$ & \\
\hline & Light activities & $0(0)$ & $9(47.37 \%)$ & \\
\hline & $\begin{array}{l}\text { Unable to perform any of the above } \\
\text { activities due to knee pain }\end{array}$ & $0(0)$ & $2(10.53 \%)$ & \\
\hline \multirow{4}{*}{$\begin{array}{l}\text { Highest activity } \\
\text { without swelling }\end{array}$} & Very strenuous activities & $3(18.75 \%)$ & $0(0)$ & \multirow[t]{4}{*}{0.000} \\
\hline & Strenuous activities & $6(37.5 \%)$ & $0(0)$ & \\
\hline & Moderate activities & $7(43.75 \%)$ & $8(42.11 \%)$ & \\
\hline & Light activities & $0(0)$ & $11(57.89 \%)$ & \\
\hline \multirow{4}{*}{$\begin{array}{l}\text { Highest activity } \\
\text { without instability }\end{array}$} & Very strenuous activities & $3(18.75 \%)$ & $0(0)$ & \multirow[t]{4}{*}{0.000} \\
\hline & Strenuous activities & $9(56.25 \%)$ & $0(0)$ & \\
\hline & Moderate activities & $4(25 \%)$ & $8(42.11 \%)$ & \\
\hline & Light activities & $0(0)$ & $11(57.89 \%)$ & \\
\hline \multirow{5}{*}{$\begin{array}{l}\text { Highest level of } \\
\text { activity }\end{array}$} & Very strenuous activities & $2(12.5 \%)$ & $0(0)$ & \multirow[t]{5}{*}{0.000} \\
\hline & Strenuous activities & $5(31.25 \%)$ & $1(5.26 \%)$ & \\
\hline & Moderate activities & $9(56.25 \%)$ & $3(15.79 \%)$ & \\
\hline & Light activities & $0(0)$ & $13(68.42 \%)$ & \\
\hline & $\begin{array}{l}\text { Unable to perform any of the above } \\
\text { activities due to knee }\end{array}$ & $0(0)$ & $2(10.53 \%)$ & \\
\hline \multirow[t]{4}{*}{ Ascending stairs } & Not difficult at all & $15(93.75 \%)$ & $3(15.79 \%)$ & \multirow[t]{4}{*}{0.000} \\
\hline & Minimally difficult & $1(6.25 \%)$ & $8(42.11 \%)$ & \\
\hline & Moderately difficult & $0(0)$ & $7(36.84 \%)$ & \\
\hline & Extremely difficult & $0(0)$ & $1(5.26 \%)$ & \\
\hline \multirow[t]{3}{*}{ Descending stairs } & Not difficult at all & $15(93.75 \%)$ & $5(26.32 \%)$ & \multirow[t]{3}{*}{0.000} \\
\hline & Minimally difficult & $0(0)$ & $8(42.11 \%)$ & \\
\hline & Moderately difficult & $0(0)$ & $5(26.32 \%)$ & \\
\hline
\end{tabular}




\begin{tabular}{|c|c|c|c|c|}
\hline Observation items & Items & $\begin{array}{l}\text { Joint } \\
\text { Preservation }\end{array}$ & $\begin{array}{l}\text { Prosthetic } \\
\text { replacement }\end{array}$ & $\begin{array}{l}P \\
\text { Value }\end{array}$ \\
\hline & Extremely difficult & $1(6.25 \%)$ & $1(5.26 \%)$ & \\
\hline \multirow[t]{5}{*}{ Kneeling } & Not difficult at all & $9(56.25 \%)$ & $1(5.26 \%)$ & \multirow[t]{5}{*}{0.002} \\
\hline & Minimally difficult & $6(37.5 \%)$ & $8(42.11 \%)$ & \\
\hline & Moderately difficult & $1(6.25 \%)$ & $4(21.05 \%)$ & \\
\hline & Extremely difficult & $0(0)$ & $4(21.05 \%)$ & \\
\hline & Unable to do & $0(0)$ & $2(10.53 \%)$ & \\
\hline \multirow[t]{5}{*}{ Squatting } & Not difficult at all & $9(56.25 \%)$ & $1(5.26 \%)$ & \multirow[t]{5}{*}{0.003} \\
\hline & Minimally difficult & $5(31.25 \%)$ & $8(42.11 \%)$ & \\
\hline & Moderately difficult & $1(6.25 \%)$ & $1(5.26 \%)$ & \\
\hline & Extremely difficult & $1(6.25 \%)$ & $5(26.32 \%)$ & \\
\hline & Unable to do & $0(0)$ & $4(21.05 \%)$ & \\
\hline \multirow{4}{*}{$\begin{array}{l}\text { Sitting with bent } \\
\text { knee }\end{array}$} & Not difficult at all & $4(25 \%)$ & $3(15.79 \%)$ & \multirow[t]{4}{*}{0.270} \\
\hline & Minimally difficult & $10(62.5 \%)$ & $8(42.11 \%)$ & \\
\hline & Moderately difficult & $2(12.5 \%)$ & $5(26.32 \%)$ & \\
\hline & Extremely difficult & $0(0)$ & $3(15.79 \%)$ & \\
\hline \multirow[t]{3}{*}{ Rising from chair } & Not difficult at all & $15(93.75 \%)$ & $4(21.05 \%)$ & \multirow[t]{3}{*}{0.000} \\
\hline & Minimally difficult & $1(6.25 \%)$ & $11(57.89 \%)$ & \\
\hline & Moderately difficult & $0(0)$ & $4(21.05 \%)$ & \\
\hline \multirow{5}{*}{$\begin{array}{l}\text { Running straight } \\
\text { ahead }\end{array}$} & Not difficult at all & $14(87.5 \%)$ & $0(0)$ & \multirow[t]{5}{*}{0.000} \\
\hline & Minimally difficult & $2(12.5 \%)$ & $5(26.32 \%)$ & \\
\hline & Moderately difficult & $0(0)$ & $4(21.05 \%)$ & \\
\hline & Extremely difficult & $0(0)$ & $2(10.53 \%)$ & \\
\hline & Unable to do & $0(0)$ & $8(42.11 \%)$ & \\
\hline \multirow{4}{*}{$\begin{array}{l}\text { Jumping and } \\
\text { landing }\end{array}$} & Not difficult at all & $5(93.75 \%)$ & $0(0)$ & \multirow[t]{4}{*}{0.000} \\
\hline & Minimally difficult & $10(62.5 \%)$ & $5(26.32 \%)$ & \\
\hline & Moderately difficult & $1(6.25 \%)$ & $4(21.05 \%)$ & \\
\hline & Extremely difficult & $0(0)$ & $2(10.53 \%)$ & \\
\hline
\end{tabular}




\begin{tabular}{|lllll|}
\hline Observation items & Items & $\begin{array}{l}\text { Joint } \\
\text { Preservation }\end{array}$ & $\begin{array}{l}\text { Prosthetic } \\
\text { replacement }\end{array}$ & $\begin{array}{c}\boldsymbol{P} \\
\text { Value }\end{array}$ \\
\hline & Unable to do & $0(0)$ & $8(42.11 \%)$ & \\
\hline $\begin{array}{l}\text { Stopping and } \\
\text { starting }\end{array}$ & Not difficult at all & $6(37.5 \%)$ & $0(0)$ & 0.000 \\
\cline { 2 - 4 } & Minimally difficult & $10(62.5 \%)$ & $5(26.32 \%)$ & \\
\cline { 2 - 4 } & Moderately difficult & $0(0)$ & $4(21.05 \%)$ & \\
\hline & Extremely difficult & $0(0)$ & $2(10.53 \%)$ \\
\hline
\end{tabular}

\section{Discussion}

In recent years, with the improvement of the survival and limb salvage rates after neoadjuvant chemotherapy, considerations on improving limb function on the premise of complete resection of the tumor should be made. Joint-preservation limb salvage (JPLS) is an effective method for treating osteosarcoma of limbs in children and adolescents. It was first used in epiphysis-preservation limb salvage (EPLS) for malignant bone tumors in children[10]. Amitani et al. then proposed a limb salvage procedure that preserves the knee joint[11]. In a recent study, Takeuch et al. called it joint-preserving surgery (JPS)[12]. In the past decade, our team has been studying and improving this surgical approach [13-16], and because of the rise of the patient's age and the closure of the physis, we named it jointpreservation limb salvage.

In this study, 19 patients with OS who underwent the JPLS were followed-up 12-228 (median 62) months and had an MSTS score of 27 (range 24 to30) points. From 2009 until now, our team has committed to the clinical study of JPLS, fully confirming that joint-preservation biological reconstruction surgery after receiving neoadjuvant chemotherapy can achieve a good prognosis and limb function in patients[6]. During this period, other studies also reported a higher limb function score. Tsuchiya et al. classified osteosarcoma around the knee joint and then maximally preserved the epiphysis according to the size of the extent of tumor invasion of the epiphysis. Twenty patients obtained good limb function and a lower local recurrence rate after joint-preserving surgery by different means[7]. Chen et al. performed a jointsparing hemicortical resection and biological reconstruction in six patients with high-grade osteosarcoma, and the postoperative MSTS score was as high as $97.7 \%[17]$. Their team preserved the anterior and posterior cruciate ligaments and one of the collateral ligaments on both sides, and argued the higher MSTS score was due to knee stability. Wong et al. applied computer navigation technology to achieve accurate bone resection and preserve the epiphysis as much as possible. They applied a special tumor prosthesis to repair neoplastic bone defects in four patients aged 6 to 14 years, of whom one died of lung metastasis five months after surgery, and the remaining three patients were followed up for 26 , 45.7, and 52.3 months, with an MSTS limb function score of 30[18]. 
At present, most studies[13,17-19] have confirmed that under the premise of ensuring that tumor resection meets the requirements of safety, the implementation of JPLS will not reduce patients' survival rate or increase the postoperative recurrence rate and the occurrence of complications. On the contrary, it brings better limb function. Furthermore, since the tumor bone inactivation site does not involve the articular surface cartilage and the articular surface cartilage and surrounding soft tissues are preserved as much as possible, so there is no significant impact on the knee joint function in the later stage.

Therefore, we argue that the reconstruction concept of JPLS should be prioritized in clinical practice under strict adherence to effective neoadjuvant chemotherapy.

The contents of JPLS include epiphysial-preservation tumor segment bone resection and bone defect repair, and because the used tumor segment bone has the advantages of lower rejection, low price, and good bone healing, we generally use inactivated tumor segment bone to repair bone defects.At present, the main modes of bone inactivation in the tumor segment are liquid nitrogen freezing [20], hypertonic saline [21] external radiotherapy[22], and alcohol[14]. Sung et al. experimentally demonstrated that 95\% of alcohol can completely kill tumor cells without interfering with osteogenesis and effectively preserves joint function[23]. A pilot study by our team in ten patients with OS treated with JPLS and using $99 \%$ alcohol resulted in one patient dying of local recurrence and multiple metastases 13 months after surgery, three patients dying due to multiple metastases 9,12 , and 24 months after surgery, and three patients required reoperation due to inactivated bone fractures, with a mean International Society of Limb Salvage (ISOLS) graft score of 31 (87\%) and a mean Musculoskeletal Tumor Society (MSTS) functional score of $23(77 \%)$ at the last follow-up[13]. In this study, 16 patients with osteosarcoma around the knee joint were treated with alcohol-inactivated bone replantation.Four patients underwent open reduction and internal fixation with an embracing fixator due to inactivated bone fracture 2-9 months after surgery. One patient underwent extended resection of the tumor due to two soft tissue recurrences within 11 months after surgery. Finally, five patients were followed up for 12 months after surgery without abnormalities.

We found that the MSTS limb function score in the joint-preservation group was higher than that in the prosthesis-replacement group, consistent with a previous study by Chen et al. [16]. In their MSTS function evaluation of 90 osteosarcoma patients, the biological reconstruction and joint-preservation scores (25.0 \pm 3.3 and $25.1 \pm 3.6$ ) were significantly higher than the mechanical reconstruction and joint resection scores $(23.4 \pm 3.7$ and $23.1 \pm 3.4, P<0.05)$. San-Julian and Vazquez-Garcia retrospectively analyzed the data of patients who underwent bone tumor arthrotomy over 30 years and found that joint-preservation resulted in a higher MSTS score than joint fusion and prosthesis implantation in the long run.[24] Kensaku et al. investigated patient satisfaction after JPLS and JRLS. They found that MSTS and TESS scores were significantly higher in the JPLS group, indicating that these patients were more satisfied with limb function.[25]

At present, the evaluation of the quality of life of patients with OS undergoing different surgical methods mainly involves the difference between limb preservation and amputation [26-29], and there are few surveys and studies on the quality of life after joint preservation. Therefore, in this study, we applied the 
SF-36 to observe patients' quality of life after different limb preservation methods. Xu et al. found no significant difference in patients' quality of life with various limb salvage methods.[15] However, we found that the joint-preservation group's physical function and social function scores were higher than those of the prosthesis-replacement group, indicating that the physical function and social function related to the quality of life of the joint-preservation group were improved. These data are consistent with the study results by Kensaku et al.[30], who investigated the SF-36 scores in 62 patients with osteosarcoma after limb preservation. The physical functioning domain of the SF-36 score is a measure of whether a patient's health status prevents regular physical activity, which can also reflect limb motor function. Social functioning is used to measure the impact of physical and psychological problems on the quantity and quality of social activities and evaluate the effect of health on social activities. Therefore, JPLS may results in a better life satisfaction than JPRS, but more research is needed to confirm this conclusion.

Previous studies have found good knee range of motion and function after joint preservation [31, 32], and to further explore the knee function status after JPLS, our study also added the IKDC score to evaluate the postoperative joint function and movement. The IKDC score provides a comprehensive evaluation of the subjective symptoms and objective signs of the knee system and applies to various knee conditions. In the past, the IKDC score was mainly used for assessing ligament and tendon injuries, particularly for anterior cruciate ligament injuries and defects [33,34], and has not been used to evaluate knee joint function after limb salvage for bone tumors. We showed that the IKDC score of the joint-preservation group was higher than that of the prosthesis-replacement group. Further analysis of the differences in each item of the IKDC score for completing various daily movements and sports conditions between the two groups showed that, except for the sitting with a bent knee, the joint-preservation group scores were superior, confirming that patients after JPLS could live and exercise similar to healthy subjects. Gerhard et al.[35] found in a long-term follow-up of 30 patients with Ewing sarcoma that $83 \%$ of the patients could perform regular sports activities. For those, the weekly time spend on sports depended on the type of surgery performed, with the joint-preservation group scoring higher in terms of sports time and activity scores than those in the prosthesis reconstruction group. Therefore, biological reconstruction might lead to the ability to perform high-impact sports. In this study, by analyzing the effect of knee joint function on daily life and movement using the IKDC score, we have obtained a deeper understanding of the effect of JPLS on limb function status. Furthermore, the postoperative efficacy evaluation of JPLS is limited to joint function and the stability and movement ability of the knee joint should be focused on.

This study has some limitations, such as a non-uniform follow-up time and small sample size, resulting in potential errors in scale scores. In addition, this study did not systematically analyze the complications and prognosis of JPLS. The study subjects only involved surviving patients with osteosarcoma and lacked functional evaluation of dead patients, which may have biased the overall efficacy evaluation of JPLS.

\section{Conclusion}


This study showed that JPLS performed better than JPRS in limb function, knee function and quality of life after surgery. In evaluating postoperative efficacy in patients with osteosarcoma, it is recommended to use a combination of multiple evaluation indicators to reflect the clinical efficacy comprehensively.

\section{Abbreviations}

JPLS:Joint-preservation limb salvage.JPRS:Joint-prosthesis replacement surgery.MSTS:the Musculoskeletal Tumor Society.IKDC:International Knee Documentation Committee.SF-36:the Medical Study 36-item short-form health outcomes survey questionnaire.

\section{Declarations}

\section{Ethics approval and consent to participate}

This study has been approved by the Ethic Committee of the 960th Hospital of the People's Liberation Army[(2020) Scientific Research Ethics Review No. (74)]. Written in formed consent was obtained from all patients included in the study.

\section{Consent for publication}

Written informed consent for publication were obtained from patients.

\section{Availability of data and materials}

The date that support the findings of this study are available from the corresponding author upon reasonable request.

\section{Competing interests}

The authors declare that they have no competing interests.

\section{Funding}

The author(s) received no financial support for the research, authorship, and/or publication of this article.

\section{Authors' contributions}

ZWH did the study, analyzed the data, and wrote the manuscript. WZB,MingX,KaiZ,XCY were involved in the design, data management, and analysis of the study. All authors read and approved the final manuscript.

\section{Acknowledgements}

Not applicable 


\section{References}

1. Gill J, Ahluwalia MK, Geller D, Gorlick R. New targets and approaches in osteosarcoma. Pharmacol Ther. 2013;137:89-99.

2. Expert Committee of Osteosarcoma, Chinese Society of Clinical Oncology (CSCO). Sarcoma Committee of Chinese Association against Cancer. Consensus of clinical experts on typical osteosarcoma. J Clin Oncol.17.2012:931-933.

3. Heisel C, Kinkel S, Bernd L, Ewerbeck V. Megaprostheses for the treatment of malignant bone tumours of the lower limbs. Int Orthop. 2006;30:452-7.

4. Xu M, Wang Z, Yu X-C, Lin J-H, Hu Y-C. Guideline for Limb-Salvage Treatment of Osteosarcoma. Orthop Surg. 2020;12:1021-9.

5. Tsuchiya H, Abdel-Wanis ME, Tomita K. Biological reconstruction after excision of juxta-articular osteosarcoma around the knee: a new classification system. Anticancer Res. 2006;26:447-53.

6. Xu M, Xu SF, Yu XC. Clinical analysis of osteosarcoma patients treated with high-dose methotrexatefree neoadjuvant chemotherapy. Curr Oncol. 2014;21:e678-84.

7. Enneking WF, Dunham W, Gebhardt MC, Malawar M, Pritchard DJ. A system for the functional evaluation of reconstructive procedures after surgical treatment of tumors of the musculoskeletal system. Clin Orthop Relat Res. 1993;:241-6.

8. Ebrahimzadeh MH, Makhmalbaf H, Golhasani-Keshtan F, Rabani S, Birjandinejad A. The International Knee Documentation Committee (IKDC) Subjective Short Form: a validity and reliability study. Knee Surg Sports Traumatol Arthrosc. 2015;23:3163-7.

9. McHorney CA, Ware JEJ, Lu JF, Sherbourne CD. The MOS 36-item Short-Form Health Survey (SF-36): III. Tests of data quality, scaling assumptions, and reliability across diverse patient groups. Med Care. 1994;32:40-66.

10. Cañadell J, Forriol F, Cara JA. Removal of metaphyseal bone tumours with preservation of the epiphysis. Physeal distraction before excision. J Bone Joint Surg Br. 1994;76:127-32.

11. Amitani A, Yamazaki T, Sonoda J, Tanaka M, Hirata H, Katoh K, et al. Preservation of the knee joint in limb salvage of osteosarcoma in the proximal tibia. A case report. Int Orthop. 1998;22:330-4.

12. Takeuchi A, Yamamoto N, Hayashi K, Matsubara H, Miwa S, Igarashi K, et al. Joint-preservation surgery for pediatric osteosarcoma of the knee joint. Cancer Metastasis Rev. 2019;38:709-22.

13. Yu X, Xu M, Xu S, Song R. Long-term outcomes of epiphyseal preservation and reconstruction with inactivated bone for distal femoral osteosarcoma of children. Orthop Surg. 2012;4:21-7.

14. Yu X-C, Xu S-F, Xu M, Liu X-P, Song R-X, Fu Z-H. Alcohol-inactivated autograft replantation with joint preservation in the management of osteosarcoma of the distal femur: a preliminary study. Oncol Res Treat. 2014;37:554-60.

15. Xu S, Yu X, Xu M, Fu Z, Chen Y, Sun Y, et al. Limb function and quality of life after various reconstruction methods according to tumor location following resection of osteosarcoma in distal femur. BMC Musculoskelet Disord. 2014;15:453. 
16. Chen Y, Yu X-C, Xu S-F, Xu M, Song R-X. Impacts of Tumor Location, Nature and Bone Destruction of Extremity Osteosarcoma on Selection of Limb Salvage Operative Procedure. Orthop Surg. 2016;8:139-49.

17. Chen W-M, Wu P-K, Chen C-F, Chung L-H, Liu C-L, Chen T-H. High-grade osteosarcoma treated with hemicortical resection and biological reconstruction. J Surg Oncol. 2012;105:825-9.

18. Wong KC, Kumta SM. Joint-preserving tumor resection and reconstruction using image-guided computer navigation. Clin Orthop Relat Res. 2013;471:762-73.

19. Muscolo DL, Ayerza MA, Aponte-Tinao LA, Ranalletta M. Partial epiphyseal preservation and intercalary allograft reconstruction in high-grade metaphyseal osteosarcoma of the knee. J Bone Joint Surg Am. 2005;87(Suppl 1 Pt 2):226-36.

20. Higuchi T, Yamamoto N, Nishida H, Hayashi K, Takeuchi A, Kimura H, et al. Knee joint preservation surgery in osteosarcoma using tumour-bearing bone treated with liquid nitrogen. Int Orthop. 2017;41:2189-97.

21. Qu H, Guo W, Yang R, Li D, Tang S, Yang Y, et al. Reconstruction of segmental bone defect of long bones after tumor resection by devitalized tumor-bearing bone. World J Surg Oncol. 2015;13:282.

22. Nakamura T, Abudu A, Grimer RJ, Carter SR, Jeys L, Tillman RM. The clinical outcomes of extracorporeal irradiated and re-implanted cemented autologous bone graft of femoral diaphysis after tumour resection. Int Orthop. 2013;37:647-51.

23. Sung HW, Wang HM, Kuo DP, Hsu WP, Tsai YB. EAR method: an alternative method of bone grafting following bone tumor resection (a preliminary report). Semin Surg Oncol. 1986;2:90-8.

24. San-Julian M, Vazquez-Garcia B. Biological Reconstruction in Bone Sarcomas: Lessons from Three Decades of Experience. Orthop Surg. 2016;8:111-21.

25. Abe K, Yamamoto N, Hayashi K, Takeuchi A, Kato S, Miwa S, et al. Determining Patient Satisfaction and Treatment Desires in Patients With Musculoskeletal Sarcoma of the Knee After Jointpreservation Surgery Using a Questionnaire Survey. Anticancer Res. 2019;39:1965-9.

26. Solooki S, Mostafavizadeh Ardestani SM, Mahdaviazad H, Kardeh B. Function and quality of life among primary osteosarcoma survivors in Iran: amputation versus limb salvage. Musculoskelet Surg. 2018;102:147-51.

27. Aksnes LH, Bauer HCF, Jebsen NL, Follerås G, Allert C, Haugen GS, et al. Limb-sparing surgery preserves more function than amputation: a Scandinavian sarcoma group study of 118 patients. J Bone Joint Surg Br. 2008;90:786-94.

28. Yonemoto T, Ishii T, Takeuchi Y, Kimura K, Hagiwara Y, Iwata S, et al. Evaluation of quality of life (QOL) in long-term survivors of high-grade osteosarcoma: a Japanese single center experience. Anticancer Res. 2007;27:3621-4.

29. Bekkering WP, van Egmond-van Dam JC, Bramer JAM, Beishuizen A, Fiocco M, Dijkstra PDS. Quality of life after bone sarcoma surgery around the knee: A long-term follow-up study. Eur J Cancer Care (Engl). 2017;26. 
30. Abe K, Yamamoto N, Hayashi K, Takeuchi A, Kato S, Miwa S, et al. Satisfaction After Jointpreservation Surgery in Patients With Musculoskeletal Knee Sarcoma Based on Various Scores. Anticancer Res. 2019;39:1959-64.

31. Pesenti S, Peltier E, Pomero V, Authier G, Roscigni L, Viehweger E, et al. Knee function after limb salvage surgery for malignant bone tumor: comparison of megaprosthesis and distal femur allograft with epiphysis sparing. Int Orthop. 2018;42:427-36.

32. Kiss S, Terebessy T, Szöke G, Kiss J, Antal I, Szendröi M. Epiphysis preserving resection of malignant proximal tibial tumours. Int Orthop. 2013;37:99-104.

33. Choi W, Kim JH, Byun S-E, Ryu H-S, Rojas D. Effect of preoperative vitamin D deficiency on functional outcomes after high tibial osteotomy: a retrospective case control study. BMC Musculoskelet Disord. 2020;21:251.

34. Magnitskaya N, Mouton C, Gokeler A, Nuehrenboerger C, Pape D, Seil R. Younger age and hamstring tendon graft are associated with higher IKDC 2000 and KOOS scores during the first year after ACL reconstruction. Knee Surg Sports Traumatol Arthrosc. 2020;28:823-32.

35. Hobusch GM, Lang N, Schuh R, Windhager R, Hofstaetter JG. Do patients with ewing's sarcoma continue with sports activities after limb salvage surgery of the lower extremity? Clin Orthop Relat Res. 2015;473:839-46.

\section{Figures}

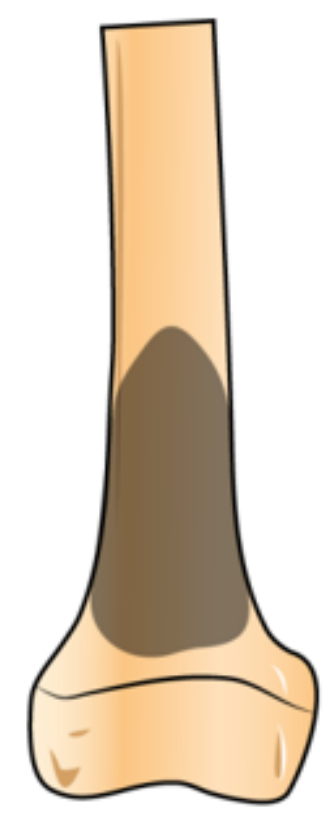

Type I

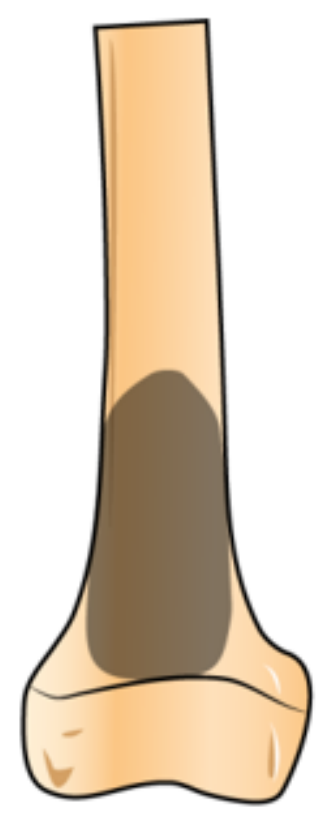

Type II

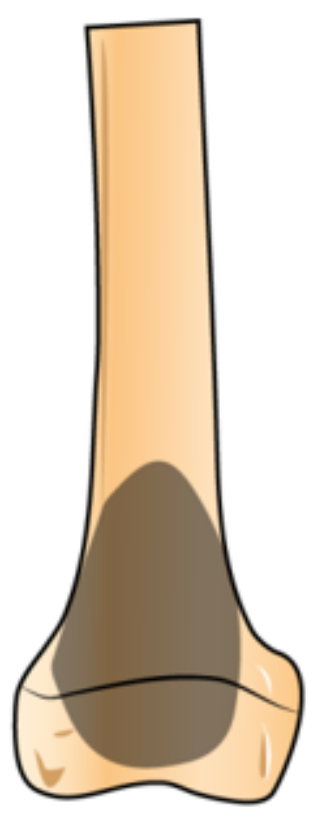

Type III

Figure 1 
Classification of tumor location according to preoperative MRI
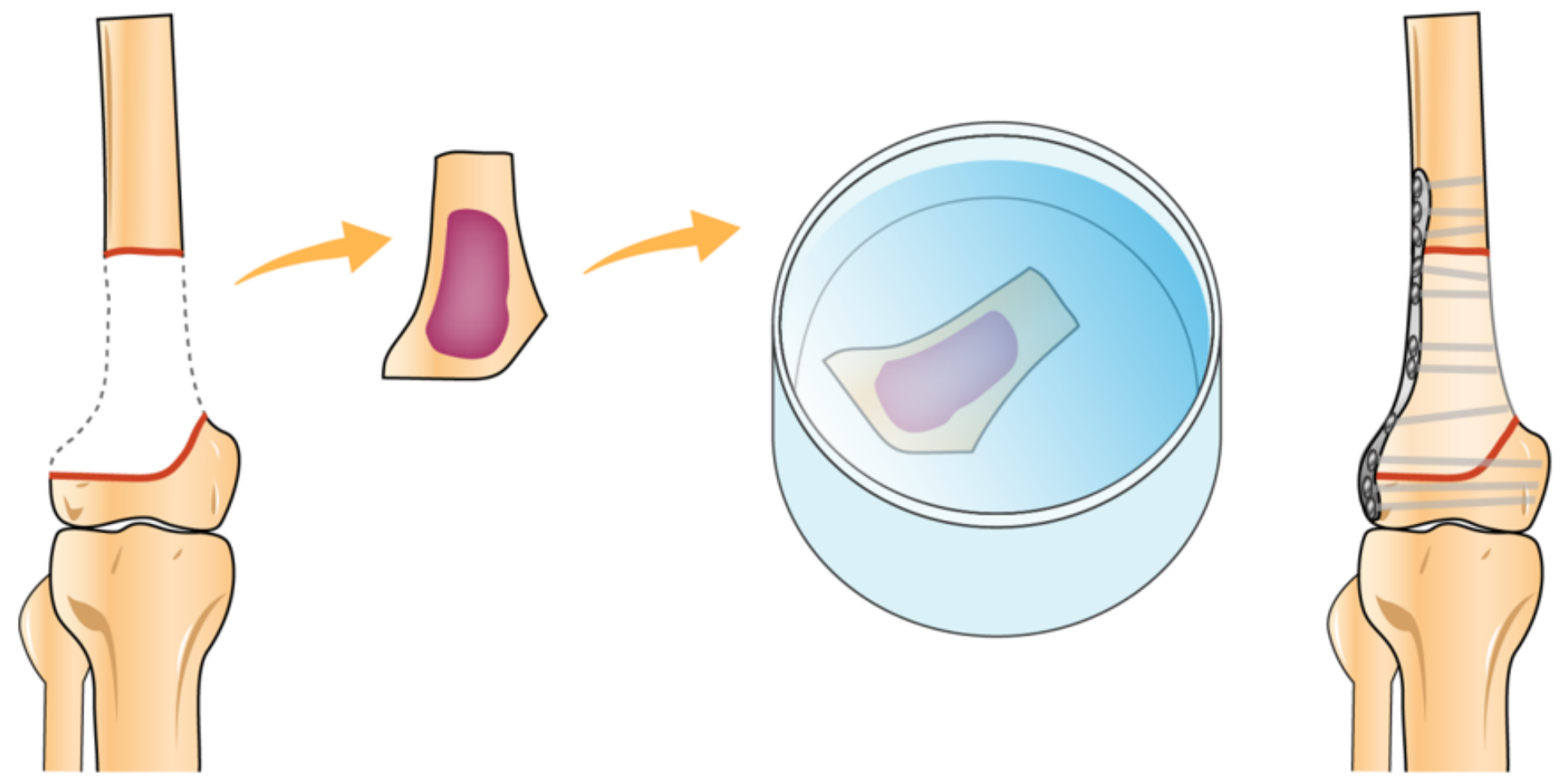

Figure 2

Schematic diagram of alcohol inactivation

\section{Supplementary Files}

This is a list of supplementary files associated with this preprint. Click to download.

- Additionalfile1.pdf 